\title{
Facioscapulohumeral Muscular Dystrophy
}

National Cancer Institute

\section{Source}

National Cancer Institute. Facioscapulohumeral Muscular Dystrophy. NCI Thesaurus.

Code C84704.

An autosomal dominant disorder affecting the skeletal muscles of the face, scapula, and upper arm. Patients present with muscle weakness in these anatomic areas. The muscle weakness eventually spreads to other skeletal muscles as well. 